\title{
HERMENÉUTICA Y EXISTENCIA EN EL CUARTO EVANGELIO
}

\author{
DIEGO S. GARROCHO SALCEDO \\ Universidad Autónoma de Madrid
}

\begin{abstract}
RESUMEN: En el presente artículo tratamos de justificar la presencia de una hermenéutica existencial en uno de los textos fundacionales de nuestra tradición: el Prólogo del Evangelio de Juan. Para ello, planteamos una interpretación crítica de las traducciones clásicas de dicho texto e intentamos defender que la escatología joánica no atiende a un emplazamiento cronológico sino a otro preferentemente espacial. A lo largo de nuestro estudio examinaremos el uso y la traducción de las preposiciones en el Prólogo y la Carta Primera para subrayar la función sígnico-existencial de la Encarnación del Hijo. A partir de esta hipótesis, reconstruiremos una interpretación a través de la cual el Prólogo del Evangelio de Juan puede y debe interpretarse como un precedente remoto y fundacional de una de los marcos filosóficos más relevantes del siglo xx: la hermenéutica de la existencia.
\end{abstract}

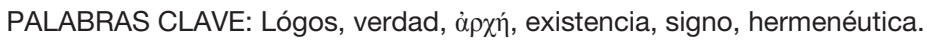

\section{Hermeneutic and Existence in the Fourth Gospel}

ABSTRACT: In this paper we aim to justify the presence of an existencial hermeneutics in one of the foundational texts of Christian, or Judeo-Christian tradition: the Prologue to the Gospel of John. To this end, we raise a critic interpretation of the classical translations of the text and try to verify that the Saint John's eschatology does not meet a chronological emplacement but a spatial one. Throughout this work we examine the use of prepositions in the Prologue and the First Letter in order to remark the signifying and existential function of the Incarnation Starting from this hypothesis we aim to defend that the Prologue to the Gospel of John states a foundational, albeit chronologically distant, precedent of one of the most relevant philosophical frameworks in the 20th century continental philosophy: the hermeneutics of existence.

KEY WORDS: Logos, Truth, ג̇pxฑ́, Existence, Sign, Hermeneutics.

A Jorge Pérez de Tudela

\section{INTRODUCCIÓN}

Pocos textos de la tradición Bíblica han convocado la atención de los filósofos con tanta insistencia como el Prólogo al Evangelio de Juan ${ }^{1}$. De San Agustín ${ }^{2}$ al idealismo alemán ${ }^{3}$, pasando por célebres pasajes de la literatura como aquel del Fausto en el que el

1 Jn 1, 1-18.

2 La exégesis agustiniana del Cuarto Evangelio queda recogida en obras como De Trinitate, De Civitate Dei, Confesiones y Sermones además de abordarse, de un modo enteramente explícito y monográfico, en el Tractatus in Iohannis Evangelium.

3 Fichte recoge su particular interpretación del prólogo joánico en la lección sexta de sus Die Anweisung zum seligen Leben, oder auch die Religionslehre. Del mismo modo, Hegel incorporará notas de evidente inspiración joánica a en su Historia de Jesús así como en su Ciencia de la lógica. Mención especial merece, desde luego, la lectura de Schelling recogida en Urfassung der Philosophie der Offenbarung. Cfr. Pérez-Borbujo, F. «El lógos del amor: Filosofía y Religión en el Idealismo alemán» en Ars Brevis: anuario de la Càtedra Ramon Llull Blanquerna, No. 11, 2005, pp. 31-66 y DuQue, F. La era de la crítica, VII.5.4. Especialmente relevante, a este respecto, resulta el artículo publicado por F. Duque en esta misma revista bajo el título «El inicio del habla, el habla del inicio», Pensamiento, Vol. 69, No . 259, 2013, pp. 197-212. 
héroe se esforzaba agónicamente por encontrar una traducción correcta de los primeros versos del Prólogo, muchos han sido los intentos por desentrañar aquellos versos que condensan, casi en exclusiva, dogmas tan relevantes para la doctrina Cristiana como son la Encarnación o la Trinidad. El interés, sin embargo, no ha nacido —o no exclusivamente- de la preocupación de los filósofos por incorporar la aportación joánica a la eventual conciliación entre fe y razón. Es indudable que el Prólogo de Juan es un texto privilegiado a la hora de justificar, de tantos modos como fuera posible, la semejanza entre en conocimiento humano y la revelación divina. Cabe, sin embargo, una interpretación puramente filosófica que se hace no sólo posible sino necesaria por cuanto aquel prólogo —o si se prefiere, por su estructura, también poema- debuta mencionando el que probablemente sea el concepto más indescifrable, hermético y polisémico — pero, paradójicamente, también vertebral- del pensamiento griego: el lógos. Por una suerte de azar geográfico aquel lógos del Prólogo joanino ('Ev ả $\rho \chi \tilde{n} \tilde{\eta} v$ ó $\lambda o ́ \gamma o \varsigma)^{4}$ se asemeja a ojos de cualquier intérprete a aquel otro, acuñado también en Éfeso, y que nos recuerda por

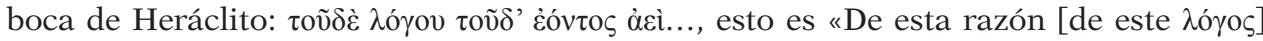
que existe siempre.... $\aleph^{5}$ situándonos, ya de inicio, ante una dificultad interpretativa. El de Juan es, con mucho, el Evangelio más original, críptico y fecundo y, tal vez por ello, el de mayor atractivo hermenéutico. Recordemos, a este respecto, el viejo adagio latino que nos advertía que in claris non fit interpretatio para descubrir que la interpretación de este Evangelio convoca no sólo al teólogo sino a cualquier lector que se interrogue por el sentido subyacente en aquellos conceptos que, antes de ser bíblicos, entramaron

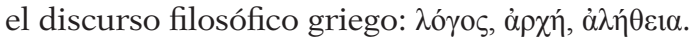

Dijo el de Hipona que las palabras joánicas resultan «tan secretas y profundas para la inteligencia que turban a los que son de corazón perverso y fortalecen, en cambio, los corazones rectos ${ }^{6}$. Puede ser que el que escribe se encuentre, sin duda, entre los primeros, pero la oscuridad del texto se impone sobre las capacidades de todo intérprete ya que también el Padre de la Iglesia nos recuerda: «nec ipse Ioannes dixit ut est, sed et ipse ut putuit», esto es, que ni el mismo Juan lo dijo «como es sino, tan sólo, como pudo decirlo» ${ }^{7}$. El ser y el decir constituyen una íntima cópula que Aristóteles fijó con precisión al señalar que la verdad —una verdad expresada en los mismos términos con los que Pilatos interrogó a Jesús ${ }^{8}$ - es, precisamente «decir de lo que es que es y de lo que no es que no es» ${ }^{9}$. Como bien diría G. Steiner ${ }^{10}$ : así hasta Nietzsche. Pero fue Nietzsche, y tras de él se inauguró una nueva manera de pensar aquel acta fundacional ${ }^{11}$ del pensamiento filosófico y que había establecido una correspondencia entre el lenguaje, el pensamiento y el mundo. Hoy somos por ello herederos si no de un pecado sí al menos de una tentación legítima que nos invita a enfrentarnos a las palabras ( $\gamma \rho \alpha \varphi \alpha i)$ de Juan de un modo distinto. En este sentido, el Prólogo se impone como un datum antes de ser Buena Nueva

Jn $1.1 \mathrm{~b}$.

5 Diels y Kranz, 1. En las citas de fragmentos presocráticos nos serviremos, de aquí en adelante, de la traducción de Alberto Bernabé (Madrid: Alianza Editorial, 1988).

6 Tract. In Joannis Evangelium 18.1 PL 34, 1535.

7 Ibid. I.I.

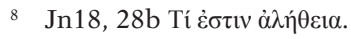

9 Met.1011b25.

10 Real Presences. Chicago: Chicago University Press, 1989. La expresión original inglesa reza: «so Nietzsche (and many after him)». Aquí, sin embargo, reseñamos la traducción castellana para le editorial Destino con una cita que ha llegado a hacerse célebre (Barcelona: Destino, 1992).

${ }_{11}$ No podemos dejar de recordar, a este respecto, las palabras de Parménides en el fragmento 3 de su Poema. 
( $\varepsilon \dot{u}-\alpha \gamma \gamma \varepsilon \dot{\lambda} 10 v)$ y se demuestra con ello, de modo prioritario, como aquello que en un sentido más puro, nunca dejó de ser: un texto.

La estrategia a seguir con vistas a desentrañar el sentido del prólogo exige determinar primeramente su ubicación contextual ${ }^{12}$. Así, al caracterizar como prólogo los diecisiete primeros versículos del Evangelio de Juan podría entenderse que en esta obertura habrían de condensarse las ideas principales o, al menos, la clave interpretativa que regirá el sentido del resto del Evangelio. En tal caso, el prólogo joánico sería un verdadero exordio que habría de confrontarse con el conjunto de doctrinas contenidas en los capítulos siguientes. Este gesto, en apariencia menor, es ya en sí mismo una toma de posición que habrá de determinar nuestra interpretación del texto y que, sin embargo, dista mucho de ser neutral. Autores como E. D. Miller ${ }^{13}$ sostienen, sin embargo, que el Evangelio fue escrito en primer lugar, seguido de la Primera Epístola joánica, por lo que el prólogo sería el último de los textos redactados por el Evangelista. Al amparo de dicha hipótesis, el inicio de la primera Carta sería un bosquejo o borrador que habría de servir de puente entre el Prólogo y el resto del Evangelio y habríamos de interpretar el inicio de la Epístola como una primera tentativa que tardíamente adquiriría su forma definitiva y quién sabe si perfecta. Otros autores como David A. Reed ${ }^{14}$, por el contrario, no han dudado a la hora de poner en continuidad el prólogo de Juan no ya con el resto del Evangelio sino que lo han situado en coherencia con las doctrinas recogidas en el Antiguo Testamento sirviéndose del paralelismo existente entre el inicio del Génesis ('Ev à $\chi \tilde{n} . ..)^{15}$ y el del Cuarto Evangelio.

El gran número de hipótesis explicativas acerca del origen, inspiración e influencias del Prólogo, ha generado una sobreabundancia de interpretaciones que difícilmente podrían condensarse en unas pocas páginas. Canónica resulta la colación de C. H. Do$\mathrm{dd}^{16}$ quien rastrea las posibles influencias herméticas, helenas, judías o filonianas del Cuarto Evangelio o, también, las siete interpretaciones retomadas por E. D. Miller ${ }^{17}$. Así, existen razones solventes para identificar el lógos joánico con la Palabra divina de YHWH (dabar) del AT o con el lógos de inspiración heraclítea que todo lo gobierna y que recobrará vigencia en la Estoa ${ }^{18}$; del mismo modo, no deja de resultar coherente el paralelismo entre el lógos de Juan y el de Filón de Alejandría, híbrido del platonismo y la tradición judía, como tampoco resulta improbable la lectura de otros autores que,

12 Tal es la hipótesis mantenida por R. Bultmann quien, en el inicio de su investigación, se interroga acerca de la naturaleza misma del Prólogo. Así destaca que el Prólogo no es una introducción en el sentido habitual del término ya que en él no se detalla ni el contenido ni la estructura del resto del Evangelio tal y como ocurre en el caso de Lucas. Asimismo, el prólogo reúne una lógica interior lo suficientemente cerrada y autónoma como para poder interpretarlo como un texto independiente capaz de significación. Siguiendo las palabras de R. Bowen (JBL 49, 1930, p. 298) Bultmann terminará por caracterizar el Prólogo joánico como una overture antes que como un verdadero prólogo. Cfr. The Gospel of John, Blackwell: Oxford, 1971.

13 JBL, 112/3 (1993) 445-457.

14 «How Semitic Was John? Rethinking the Hellenistic Background to John 1:1. Anglican Theological Review; otoño 2003, Vol. 85, 4, p. 709.

15 Si bien la traducción de los LXX equipara ambos textos (i.e., Jn 1,1a y Gn, 1,1.a) David A. Reed propone una traducción distinta para el texto del Génesis que, en hebreo, habría de adquirir distintos matices.

16 Vid. Dodd, C. H. Interpretación del cuarto evangelio. Madrid: Ediciones Cristiandad, 2004.

17 Ed. L. Miller. «The Johannine Origins of the Johannine Logos». Journal of Biblical Literature Vol. 112, No. 3 (otoño1993), pp. 445-457.

18 Aunque la traducción conceptual entre el lógos de la Estoa y el cristianismo apunta antes a la noción de $\pi v \varepsilon \tilde{u} \mu \alpha$. Vid. nota. 2 p. 24 Bultmann, R. Op. cit. 
como Burney ${ }^{19}$, han tratado de vincular el lógos joánico con la noción aramea (y siríaca) de memra recogida en el Tárgum que caracteriza las palabras de Dios como una forma privilegiada de hipóstasis. Todas estas hipótesis, susceptibles de ser válidas, no impiden enfrentar el texto joánico como una unidad autónoma y significativa. Es un hecho irrefutable que la estructura del Prólogo - y este rasgo es extensivo a todo el Evangeliocontiene una serie de interrupciones formales y rupturas temáticas que hacen más que probable que aquello que hoy conservamos y leemos como un texto unitario no sea más que una composición fragmentaria y alterada. Así, los versísculos 6,7,8,13 y 15 resultan del todo ajenos a la temática central del Prólogo y, como bien señalara Bultmann ${ }^{20}$, podrían situarse sin mayores problemas a continuación del inicio del Evangelio. De igual manera, resulta llamativo el salto cronológico que se recoge entre los versos 11 y 14 . Así, siguiendo una lectura lineal del texto, pareciera que el lógos «llegó a su casa y los suyos no lo recibieron ${ }^{21}$ antes de que, en efecto, se haya materializado de modo explícito la Encarnación ${ }^{22}$.

Estas y otras rupturas, temáticas y formales, han alentado durante generaciones investigaciones filológicas y teológicas con vistas a fijar, si es que tal cosa fuera posible, el sentido original que se oculta tras las oscuras y herméticas palabras del Evangelista. Esta opción, pertinente al menos, cuando no necesaria, no impide el que podamos enfrentarnos al texto joánico desde aquella posición que por simple e inmediata pudiera distinguirse como prioritaria, esto es: afrontando la lectura e interpretación del Prólogo como una unidad significativa y autónoma capaz de contener un sentido independiente, tal vez, de aquel querer decir originario que allá por el siglo primero inspiró —o no— la redacción del cuarto Evangelio. Para ello, no habría posibilidad más prudente que interpretar el Prólogo en continuidad con el resto del Evangelio concediendo que acaso no fuera sólo el azar quien fijó y determinó una estructura canónica del texto. En tal caso, la interpretación estilística y semántica de los conceptos recogidos en el Prólogo habría de poder validarse por sí misma recurriendo, todo lo más, a aquellos otros pasajes que a lo largo del Evangelio parecen vincularse con aquellos primeros diecisiete versículos. Tal es la hipótesis que, de aquí en adelante, mantendremos en nuestro estudio.

\section{Topología del LóGOS: El USO de las PREPOSICIONES}

Pocas traducciones entrañan una resistencia semejante a la del concepto de lógos. Palabra, sentido, discurso, razón, doctrina o recolección... las distintas formas en las que el lógos ha tratado expresarse en otras lenguas demuestran la dificultad de una traducción que, por lo demás, con W. Benjamin, habría de reconocerse como una tarea imposible. Ya entre Vetus Latina y Vulgata encontramos una primera diferencia, traducciones ambas al latín que nos devolvieron una distinta interpretación del inicio del Prólogo: el lógos joánico fue sermo (In primordio Sermo erat apud Deum ${ }^{23}$ ) y fue Verbum (In Principio erat Verbum, et Verbum erat apud Deum), dos traducciones que a su vez diferían del modo en que la Estoa tradujo como ratio aquello que para los griegos seguía expresándose como lógos. Quizá el modo más prudente para desentrañar el significado

\footnotetext{
19 The Aramaic Origin of Fourth Gospel. Oxford: Clarendon Press, 1922.

20 Op. cit. p. 16.

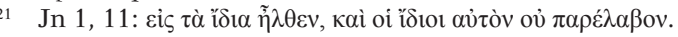

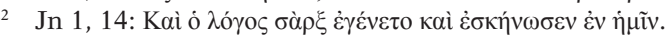

23 Tertuliano. Adversus Praxean,5 (CCSL II).
} 
de un concepto en el seno de un texto no sea otro que rastrear las cualidades que de él se expresan literalmente. En este sentido, podríamos reconstruir el sentido del lógos joánico recapitulando sus distintas descripciones, esto es, atendiendo a sus predicados. Cierto es que esta estrategia puede demostrarse poco fecunda pero nos provee, al menos, de una cierta seguridad interpretativa. Así, al enfrentarnos al Prólogo sabemos cuanto menos que es aquello que era "en principio», aunque reforzando nuestra prudencia podríamos mantenernos todavía en el decir griego. El lógos de Juan es aquello que era

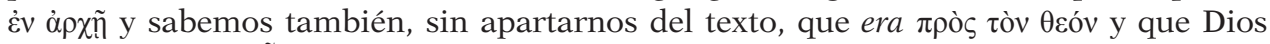
era tal lógos ( $\theta \varepsilon \dot{\varsigma} \varsigma$ ก̃v ó $\lambda$ óyos) para, después, hacerse o devenir carne.

Habrá quien piense que esta interpretación es, de suyo, tautológica o que en el mejor de los casos no estamos coleccionando otra cosa que aquello que Nietzsche supo calificar como conchas vacías ya que hasta el momento no hemos hecho más que yuxtaponer aquellos predicados derivados del término lógos. Si bien tal apreciación no deja de ser ajustada, no es menos cierto que la mitad de estos predicados acusan un rasgo común que bien pudiera adelantar algún matiz relevante en el uso del término: dos de las cuatro oraciones que mencionan al lógos en el Prólogo están regidas por el uso de una preposición. Recordamos, a este respecto, que la preposición es una palabra invariable que rige sintagmas nominales u oraciones subordinadas sustantivas por lo que su comprensión podría requerir una hermenéutica menos esforzada que si se tratara de un verbo o un sustantivo. Sin embargo, para descifrar el significado del lógos joánico se hace imprescindible desentrañar el uso que el Evangelista realiza tanto de la preposición غ̇v como de la preposición $\pi \rho$ ós.

Con respecto a la primera preposición, غ̇v, destaca enormemente el uso que el Evangelista realiza de este término que, acompañado de dativo, introduce un complemento de lugar, estado, condición... y, efectivamente, también se emplea para distinguir ubicaciones temporales. Así, en $\dot{\varepsilon} v$ à $\rho \chi \tilde{n}$ sería asimilable a la expresión «en principio» tal y como se recoge ya en la traducción de San Jerónimo (In principio...). Lo relevante, sin embargo, no es tanto la traducción del término en sí como la singularidad que entraña el hecho de que el Evangelista renunciara a emplear aquel otro término que resulta habitual en la descripción de circunstancias temporales. La diferencia, mantenida en castellano, se cifra en la distancia semántica existente entre la preposición ẻv (en) y àđó $(\text { desde })^{24}$. Esta segunda preposición es empleada profusamente en el Cuarto Evangelio para designar, precisamente, una procedencia de carácter temporal vinculándose, preferentemente, al verbo cỉuí. Así, dice el Evangelio: «Él [el demonio] era homicida desde el principio $\left(\dot{\alpha} \pi^{\prime} \dot{\alpha} \rho \chi \tilde{\eta} \varsigma\right)$ ) $\mathrm{o}$ «vosotros testificaréis, porque estáis conmigo desde el principio $\left(\dot{\alpha} \pi{ }^{\prime} \dot{\alpha} \rho \chi \tilde{\eta} \varsigma\right)^{25}$.

La concepción de lógos joánico parece aproximarse, a partir del uso de esta preposición, a un principio que no es tanto un primer elemento de una sucesión temporal

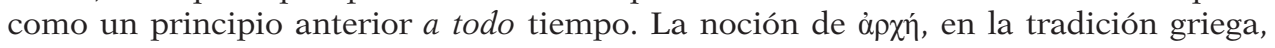
servía como referente temporal para demarcar un inicio cronológico pero su significado se extendía más allá de la estricta comprensión lineal del tiempo. A este respecto resulta paradigmático aquel proverbio retomado por Hesíodo: «el principio es más de la mitad

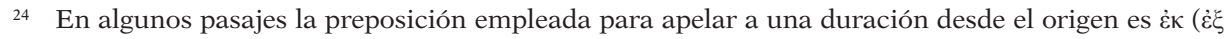
delante de vocal) como ocurre en Jn 6, 64b.: «Pues Jesús sabía desde el principio (宅 $\dot{\alpha} \rho \chi \tilde{\eta} \varsigma)$ quiénes eran los que no creían y quién era el que lo iba a entregar» y en Jn 16, 4. «Y no os dije esto desde el principio ( $\dot{\varepsilon} \xi$ $\dot{\alpha} \rho \chi \tilde{\eta} \varsigma)$, porque estaba con vosotros». Sin embargo, a lo largo del evangelio esta preposición no se emplea nunca para complementar al verbo sỉní. En ambos casos, al igual que sucediera con la expresión òd $\pi^{\prime} \dot{\alpha} \rho \chi \tilde{\eta} \varsigma$, en la Vulgata se traduce como ab initio.

25 Jn 15, 27a. Ab initio en Vulg. 
del todo» ${ }^{26}$. Al igual que ocurriera en latín y también hoy en castellano, la noción de principio subraya una prioridad cronológica pero también una prioridad de carácter ontológico. Sin embargo, como bien destaca Bultmann ${ }^{27}$, la expresión joánica difiere en el uso de la preposición de lo que habría sido el decir específicamente griego. Así, en respuesta a la cuestión del origen, tanto la tradición griega como la gnóstica habrían es-

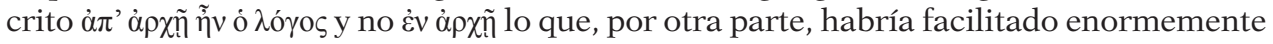
la posterior identificación entre Dios al final del versículo primero. La introducción de la preposición èv le sirvió también a H. Jonas para suspender en este punto la interpretación gnóstica del Prólogo ya que el decir joánico subraya una diferencia de relación entre el lógos y el diablo con respecto al origen. En un caso el Evangelista se sirve de la lógica preposición ả̇ó y, sin embargo, con respecto al lógos, emplea la preposición $\dot{\varepsilon} v$ lo que interrumpe oposición de contrarios previsible en un esquema de inspiración gnóstica.

Vemos, por tanto, que con la preposición غ̇v, el Prólogo parece recoger una doble referencia en la medida en que apela a una ubicación topológica — haciendo de una preposición preferentemente espacial - que, sin embargo, queda referida a un momento o localización de carácter temporal. Más allá de su función locativa, resulta principalmente significativo el uso que el Evangelista realiza de la preposición غ̇v. A lo largo del Cuarto Evangelio las referencias topológicas quedan reservadas para localizar una

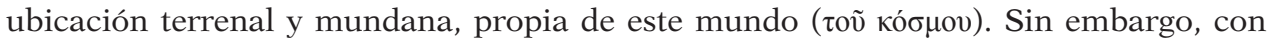
gran insistencia encontramos usos singulares de la preposición èv que, en línea con la insistente negación de este mundo, parecen apelar a otra realidad que se expresa en términos no espaciales. Un caso paradigmático lo encontramos en la ruptura que el Evangelio de Juan ejerce con respecto a la tradición judía y su consideración sagrada de la Tierra (Adamá) como lugar prometido. Así, Jesús parece enmendar esa sacralización del espacio mundano para advertir, precisamente a través del uso de la preposición locativa $\dot{\varepsilon} v$, que llegará un momento en el que «ni en este monte ni en Jerusalén [será donde] adoraréis al padre $»^{28}$ hasta precisar que llegará un tiempo en el que los verdaderos ado-

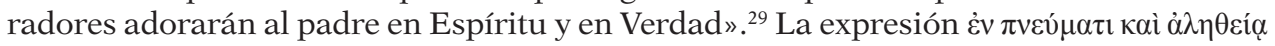

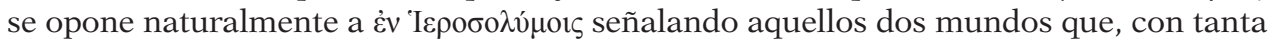
insistencia, se mencionan a lo largo de Cuarto Evangelio y la Primera Epístola ${ }^{30}$.

26 Ética Nicomáquea I, 1098b 7. Esta cita no es original de Aristóteles dado que ya Hesíodo la recoge en Los trabajos y los días, 40.

27 Op. cit. p. 31.

28 Jn 4, 21.

29 Ibid. 23.

30 Jesús precisa con su palabra esa distinción jerárquica entre este mundo y su lugar de origen. Así advierte: "vosotros sois de abajo, yo soy de arriba; vosotros sois de este mundo, yo no soy de este mundo", 8, 23 (Cfr. Jn 13, 1b «Habiendo amado a los suyos que estaban en el mundo, los amó hasta el extremo». Esta pertenencia de Jesús a otro mundo contrasta, a su vez, con el hecho de que no sea sólo su origen sino también su Reino el que pertenece a otro orden. A este respecto es enormemente reveladora la expresión en la conversación con Pilatos (Jn 18, 36): «Mi reino no es de este mundo. Si mi reino fuera de este mundo mis hombres lucharían para que yo no fuera entregado a los judíos. Pero de hecho mi reino no es el de aquí»). Sin embargo, esa pertenencia no es definitiva sino que adquiere una cualidad relativa por cuanto aquellos que son del mundo pueden ser, a su vez, liberados de él. La distinción entre dos órdenes (uno divino y otro mundano) se significa precisamente como una forma de oposición y rechazo desde un mundo hacia el otro. Por ello, señala Jesús, «si fuerais del mundo, el mundo tendría afecto a lo suyo; pero, porque no sois del mundo sino que yo os elegí [sacándoos] del mundo, por esto el mundo os odia», Jn 15,19b La censura de este mundo queda perfectamente matizada en 1 Jn 2.16 donde se advierte: «porque todo [lo que hay] en el mundo - la codicia de la carne, la codicia de los ojos y la ostentación de lo que se tiene- no procede del Padre sino que procede del mundo». Esta extracción salvífica del mundo (de este mundo) se 
Este uso de la preposición غ̇v demuestra el compromiso del Evangelista con una simbología espacial sin que por ello resolvamos la ambigüedad de un término que, en clave evangélica, hereda la ambigüedad de la preposición prefijada — be en hebreo y en arameo $^{31}$. Así, al anunciar la posibilidad de que la adoración fuera en verdad (غ̇v $\left.\dot{\alpha} \lambda \eta \theta \varepsilon \dot{c}_{i}\right)$ el Evangelista parece expresarse en términos metafóricos para señalar un complemento no sólo preposicional sino también una nota adjetiva. Se trataría, por tanto, no de adorar simplemente en un tiempo o en un lugar concreto sino de adorar "verdaderamente» o «espiritualmente». La verdad no es, pese a todo, una mera condición o atributo de la predicación sino que se significa en el Cuarto Evangelio como un lugar desde el que la palabra verdadera se profiere. A este respecto, la inexacta traducción de la cé-

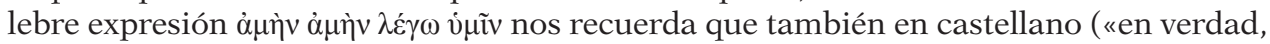
en verdad os digo») podemos apelar a una cierta direccionalidad del decir verdadero. La preocupación por el sentido o incluso, cabría pensar, la vieja y ortodoxa descripción de la verdad como una adaequatio nos impone un esquema direccional - y por tanto espacial - sobre la representación del tiempo cronológico incluso para demarcar aquello que parecía estar fuera de todo tiempo y fuera de todo lugar. La verdad ( $\dot{\alpha} \lambda \dot{\eta} \theta \varepsilon 1 \alpha)$ en el Evangelio de Juan aparece insistentemente vehiculada por el uso de las preposiciones. Un ejemplo de expresividad notable lo encontramos en el modo en el que Él distingue a sus verdaderos discípulos: el discípulo verdadero es aquel que conocerá la verdad y aquel que conocerá la verdad es aquel que permanece en el lógos ( $\dot{\varepsilon} v \tau \tilde{\omega} \lambda \hat{\gamma} \gamma \omega)^{32}$. De nuevo, esta expresión parece retomar un lenguaje locativo o direccional en el que confluyen, paradójicamente, presente y futuro. Así, el texto advierte que la verdad será conocida en un tiempo futuro pero dicho conocimiento requiere una forma de permanencia o estatismo en el lógos. Vemos, por tanto, cómo presente y futuro quedan reunidos a través de un discurso marcado por las preposiciones en las que la distinción entre «este mundo» $\mathrm{y}$ «aquel otro mundo» resulta del todo determinante.

La escisión entre estos dos órdenes parece describirse en términos más sincrónicos que diacrónicos en los que la metáfora del espacio nutre de sentido a la encarnación del Lógos. R. Bultmann ${ }^{33}$, E. Käsemann ${ }^{34}$ o A. Deissler ${ }^{35}$ subrayaron la preponderancia en el texto joánico de una escatología que Moltmann ${ }^{36}$ denominó preséntica, contraria

opera, a su vez, por medio del lógos a través de su donación: «manifesté tu nombre a los hombres que me

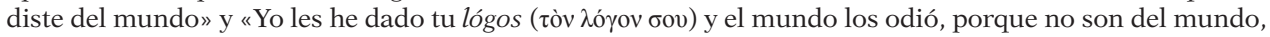
como tampoco yo soy del mundo», Jn 17,14. En este mundo, sin embargo, cabe a través de la venida del Hijo una redención lo que justifica, así, la encarnación del lógos. Según se expresa en el pasaje anterior y si ponemos en suspenso la interpretación latina que convirtió la donación del lógos en la donación de una doctrina (sermo) cabría identificar ese acto con la entrega del Hijo. Jesús es así, no sólo enviado por Dios

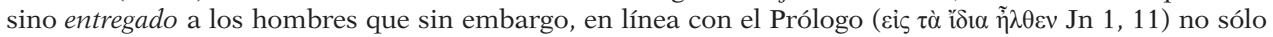
no le recibieron sino que lo condenaron. De este modo, la encarnación rebasaría su función soteriológica para alcanzar, incluso, una renaturalización del mundo. Por ello, señala Jesús: «no pido que los saques del mundo, sino que los guardes del Malo», Jn 17,6.

31 Como amablemente me indicó el profesor Rafael Jiménez Zamudio, esta preposición, en hebreo y en arameo, adquiere un valor locativo pero también instrumental. Del mismo modo, esa ambigüedad la encontramos en el idioma acadio en la preposición ina.

32 Jn 8, 31.

33 Teología del Nuevo Testamento. Op. cit. 496 y ss.

34 Ensayos exegéticos. Salamanca: Sígueme, 1978.

35 L'uomo secondo la Biblia. Per un'antropologia esegetica. Roma: Città Nuova Editrice, 1989.

36 The Coming of God: Christian Eschatology. Otros autores han llegado a afirmar que la cristología, propiamente dicha, contendría no tanto una escatología del futuro sino una escatología del tiempo pretérito. Vid. Mysterium Salutis: manual de teología como historia de la salvación: la Iglesia: el acontecimiento salvífico en la comunidad cristiana, Vol. V. Madrid: Ediciones Cristiandad, 1971, pp. 624 y ss. 
a aquella escatología futúrica que recogen los sinópticos. Sin embargo, a través de esta interpretación espacial podríamos renunciar no sólo a la escatología futúrica sino también a toda forma de escatología diacrónica. El tiempo del Cuarto Evangelio no se describe en torno a un principio y un final ni tan siquiera como límites habilitantes de una línea cronológica. Así, la arché del verso primero cobra especial sentido al interpretarse no ya como un principio temporal sino, ante todo (antes de todo) como un principio ontológico. De este modo, la dinámica interna del Evangelio de Juan se encuentra mucho más ligada a la dimensión espacial que a la dimensión temporal por cuanto ya en el Prólogo el hecho fundamental (i.e., aquel que habilita la transición entre «un mundo» y el otro) se expresa de forma pasada: el verbo se hizo carne. Por todo ello cobran especial significatividad aquellos pasajes en los que, de nuevo, el Evangelista recurre a la categoría de lugar para situar y caracterizar la verdad de la Palabra no ya como una realidad futura sino como un acto de donación ya acontecido y regido por una estaticidad cronológica y topológica. El lenguaje futúrico se sustituye así por un lenguaje centrado en la retención e incluso, valdría decir, en el cuidado y custodia de la palabra ${ }^{37}$. Jesús advierte:

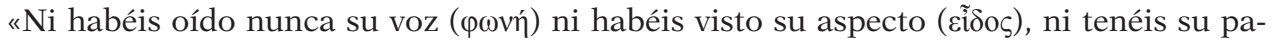
labra ( $\lambda$ ó $\left.{ }^{\circ} \varsigma\right)$ residiendo en vosotros» $(5,37-38)$. Aquella palabra que era en principio se destaca por estar ausente en el hombre hasta el momento en que pueda ser escuchada. La transición consiste no ya en abandonar el mundo puesto que los hombres se hallan todavía en el mundo ( $\dot{\varepsilon} v \tau \tilde{\omega}$ кó $\sigma \mu \omega)$ pero, sin embargo, estos hombres no serán, a partir

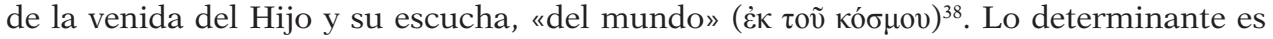
que ese momento o advenimiento no se posterga a futuro y la resignificación del tiempo por venir opera desde un presente recogido en el seno de la narración joánica. La supresión de ese éschaton futuro, capaz de escandir el tiempo, abre paso a una demarcación espacial en la que la dialéctica se determina no ya entre un ahora y un mañana sino entre un aquí y un allí, este mundo y el otro mundo, un arriba o un abajo... Resulta determinante, en este punto, el hecho de que el lógos no sea anunciado sino que se inste a su retención, una retención descrita no con ( $\mu \varepsilon \tau \alpha$ ) nosotros ni tan siquiera a través ( $\delta$ ı́ $)$ de nosotros sino, precisamente, en nosotros. La fórmula se repite con respecto al

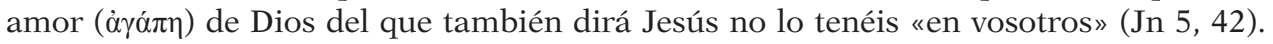
Sin embargo, es en el interior del relato donde se recoge el acontecimiento transicional mismo a partir del cual Jesús alcanza a afirmar: «El espíritu de la verdad reside [ya] entre vosotros y está en vosotros» $(14,17)$.

El kairós transicional en la historia de la Salvación parece situarse en el tiempo presente al afirmar Jesús que «ahora es el juicio de este mundo; ahora el príncipe de este mundo será echado fuera» (12:31). El tò võv del tiempo presente justifica la inauguración de un tiempo nuevo marcado no sólo por la Encarnación sino por el conocimiento de las señales ( $\sigma \eta \varepsilon \tilde{\alpha} \alpha)$ de Cristo. Así, es ahora cuando los hombres conocen o alcanzan

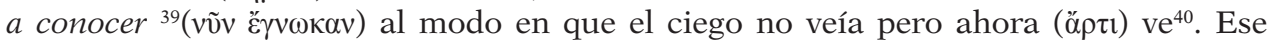

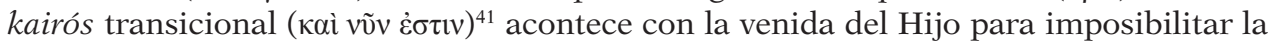

37 Así también en la Primera Epístola de Juan se advierte: «Pero la unción que vosotros recibisteis de él permanece en vosotros, y no tenéis necesidad de que nadie os enseñe; así como la unción misma os enseña todas las cosas, y es verdadera, y no es mentira, según ella os ha enseñado, permaneced en él» (1Jn 2.7) ó: «Todo aquel que es nacido de Dios, no practica el pecado, porque la simiente de Dios permanece en él; y no puede pecar, porque es nacido de Dios» (1Jn 2,27). Cfr. I Cor 1.

38 TNT. 496-97. Cfr. Jn 17, 11.14.16).

39 Jn $17,7$.

40 Jn 9,25.

41 Jn 4, 23. 
analogía entre el ciego y los hombres ya que el pecado o la salvación se justifican a partir de la visión o la audición de la Palabra. Así la condena se torna posible tras la escucha y Jesús advierte: «Si fuerais ciegos no tendríais pecado; mas ahora, porque decís vemos vuestro pecado permanece ${ }^{42}$. La clave, por tanto, no se sitúa en la Encarnación sino en la palabra, o valdría decir, en el habla. Así sentencia el Nazareno: «Si yo no hubiera

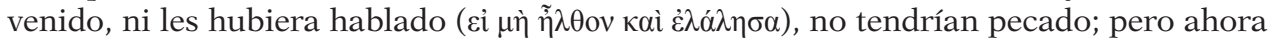
no tienen excusa por su pecado» ${ }^{43}$.

Según lo expuesto cabe concluir que la centralidad del uso de la preposición en demuestra que la escatología joánica plantea un interrogante no sólo temporal (ya sea futúrico, ya sea preséntico) sino prioritariamente topológico. La pregunta por el cuándo cede su protagonismo, al menos en parte, a la pregunta por un dónde que, pese a todo, no queda desvinculado del tiempo. La lógica de la retención o la custodia («permaneced en mi amor», "permaneced en mi lógos», "vosotros en mí, yo en el padre») nos recuerda que tiempo y espacio son dos nociones subsidiarias ya que la idea de permanencia no es más que una insistencia cronológica en un locus, una retención temporal que se ejecuta o se mantiene en un lugar dado. Así, el lógos joánico era en principio pero es también el lugar en el que habrán de mantenerse aquellos que vieron, escucharon y creyeron.

Si bien la preposición en demuestra su relevancia a partir de una traducción más o menos exenta de problemas, la comprensión de aquella otra preposición que determinaba la descripción de lógos resulta mucho más conflictiva. Sabemos que «'Ev à $\rho \chi \tilde{n}$

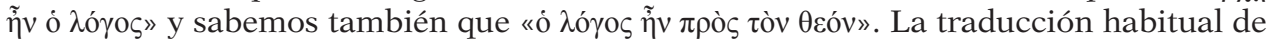
este verso, de San Jerónimo a Erasmo y así también en las lenguas vulgares, recoge una intuición que tal vez resuma en exceso el sentido original griego del decir joánico. La preposición $\pi \rho o ́ \varsigma$ en griego, al contrario que el apud latino, rige tanto acusativo como dativo y su significado es por ello variable. Siguiendo la traducción latina la mayoría de las traducciones contemporáneas señalan que el lógos era (estaba, existía...) con Dios pero esa concomitancia espacial acaso minimice el matiz incluido en la preposición griega. Con acusativo, $\pi \rho o ́ \varsigma$ significa «hacia», «frente a», «en vista de», «con relación a»... e, incluso, «contra». Prescindiendo de esta última acepción en la medida en que la oposición entre el lógos y Dios se hace imposible en este contexto, una traducción al latín posible habría sido no ya «Verbum (Sermo, Ratio...) erat apud Deum» sino «ad Deum». Intérpretes como Sixto de Siena o Tomás Cayetano ${ }^{44}$ suscribieron esta traducción manteniendo, así, una connotación direccional del todo ausente en la habitual traducción por apud. Evidentemente resulta improbable que pudiéramos resumir el sentido original de la preposición griega en cualquier otra lengua, así fuera el latín, pero no deja de resultar sorprendente la falta de coherencia interna que se da en la propia Vulgata a la hora de traducir esta preposición. Así, si rastreamos los usos de la preposición en el Evangelio y la traducción de San Jerónimo comprobaremos cómo la traducción de $\pi$ pós por ad no debería resultar escandalosa. En 12:32 ( Y yo [Jesucristo], cuando sea elevado de la

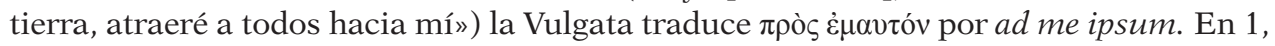

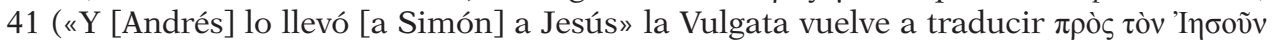

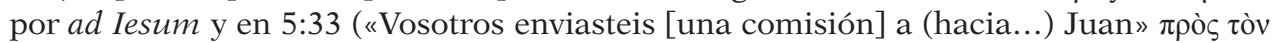

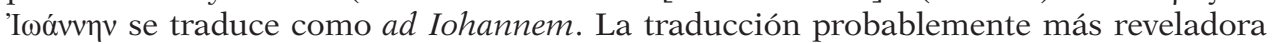
a este respecto es la que recoge la diferencia entre las dos preposiciones. Así, en 7, 33

42 Jn $9,41$.

43 Jn 15,22. Cfr. Jn 15, 24.

44 Tomás Cayetano, en su traducción de la Biblia ya escribe «In principio erat Ratio et Ratio erat ad Deum». (Cfr. R. P. D. F. JoAnnis da Sylveira. Commentarii in textum Evangelicum. V.I.I. \& Sixto de Siena. Bibliotheca Sancta. L. VI. Annotatio. CLXIX. (quien mantiene «verbum» y no «ratio»). 
( Conque Jesús dijo: “Aún estaré con vosotros un poco de tiempo; y me iré al que me

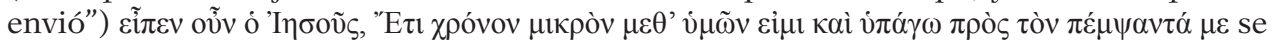
traduce por dixit ergo Iesus adhuc modicum tempus vobiscum sum et vado ad eum qui misit me. En esta oración encontramos un $\mu \varepsilon \theta^{\prime}$ v $\mu \tilde{\omega} \nu$ ( $\mu \varepsilon \tau \alpha ́$ ), que en la Vulgata se se traduce como vobiscum (i.e., cum vobis) mientras que inmediatamente después se recoge el vado ad eum qui misit me, reiterando la traducción de $\pi$ pó

A la vista de estos ejemplos ${ }^{45}$ parecería razonable interpretar el lógos de Juan no como que aquello estaba ( $\dot{\varepsilon} v$ ) con (junto a, al lado de...) Dios sino que era o estaba hacia Dios. La posibilidad de que esta traducción fuera válida vuelve a subrayar una direccionalidad en la caracterización del lógos que bien podría situarse en línea con la interpretación que habíamos reconstruido a partir del examen de la preposición èv. Sumando predicados, a partir del Evangelio de Juan sabemos que el lógos era en principio, era hacia Dios y era - a falta de resolver la ausencia del artículo determinado- era Dios mismo. A partir de estos descriptores constatamos que las notas sustantivas que definen el lógos joánico son escasas e insuficientes ya que todas las definiciones del lógos en el

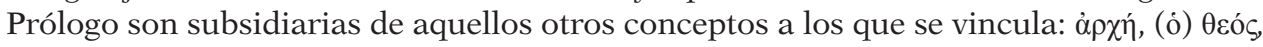
$\sigma \alpha ́ \rho \xi$. Asumiendo esta cuasi vacuidad semántica (seguimos moviéndonos en el seno de una definición cuasi analítica sin todavía resolver el sentido del concepto) no podemos más que remitirnos al contexto del Cuarto Evangelio como trasfondo general desde el que pudiera hacerse viable una reconstrucción del sentido del lógos.

\section{La EXISTENCIA SIGNIFICANTE}

Dos son las vías para habilitar la reconstrucción semántica del lógos a través del Cuarto Evangelio: su identidad con Dios y de otra su renaturalización a través de la Encarnación. Lógicamente es a través de la Encarnación como mejor podría legitimarse una continuidad semántica entre Prólogo y Evangelio si es que acaso el Lógos y el Hijo (y, subsidiariamente, Dios y el Espíritu) remiten a una misma instancia. El Hijo del Hombre es, en efecto, lógos encarnado que se expresa, precisamente, a través de palabras ( $\left.\dot{\eta} \mu \alpha \tau \alpha^{46}\right)$ o a través de una $\lambda \alpha \lambda i ́ \alpha$, esto es, de un habla o un discurso. La palabra lógos no es simplemente el medium a través del cual se expresa el contenido salvífico de la

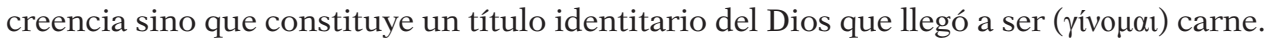
Del Jesús del cuarto Evangelio podemos extraer toda una colección de notas distintivas que harían interminable una enumeración de predicados. Por ello parece prudente comenzar por el modo en que el Nazareno se presenta a sí mismo.

Varias son las formas en las que Jesús se expresa presentándose a través de la célebre

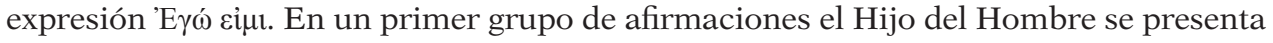
metafóricamente como pan de vida, luz verdadera o vid verdadera ${ }^{47}$. En otros pasajes su

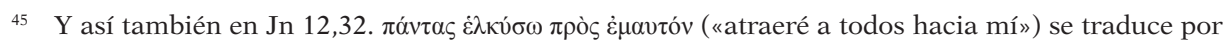
omnia traham ad me ipsum.

46 Frente a Miller, descartamos la posible identidad entre ṕn $\mu \alpha \tau \alpha$ y lógos. El término lógos, en el Cuarto Evangelio, aparece referido 39 veces por 19 del término $\rho \eta ́ \mu \alpha \tau \alpha$. Sin embargo, la identidad establecida entre el Hijo y el lógos difiere del uso preferentemente instrumental que con el que se emplea $\dot{\eta} \mu \alpha \tau \alpha$.

47 Así en: Jn 6, 35: Jesús les dijo: «Yo soy el pan de vida; el que a mí viene, nunca tendrá hambre; y el que en mí cree, no tendrá sed jamás». Jn 6,41: «Murmuraban entonces de él los judíos, porque había dicho: Yo soy el pan que descendió del cielo». Jn 6,48: "Yo soy el pan de vida». Jn 6,51: "Yo soy el pan vivo que descendió del cielo; si alguno comiere de este pan, vivirá para siempre; y el pan que yo daré es mi carne, la cual yo daré por la vida del mundo». Jn 8,12: "Yo soy la luz del mundo; el que me sigue, no 
caracterización se acoge no ya a una descripción meramente cualitativa sino funcional. Jesús se presenta así, como "puerta» o «camino» que sirve de acceso para la transición salvífica hacia el otro mundo ${ }^{48}$. Así, el Hijo del Hombre no se presenta ya como la «vida verdadera» descrita en el Prólogo sino como la mediación que conduce a dicho estado. Esta interpretación vehicular e incluso rectora ( $y$ yo soy el buen pastor» ${ }^{49}$ ) subraya la función mediadora y caracteriza al lógos encarnado como la condición necesaria y suficiente para la salvación. Estos dos grupos, sin embargo, podrían quedar resumidos en la que acaso sea la más perfecta caracterización del Hijo en primera persona: 'E $\gamma \omega \dot{~ \varepsilon i ̀ u ~}$

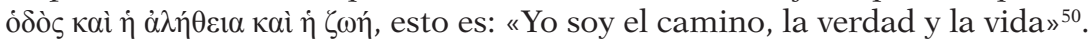

Finalmente, un último grupo de afirmaciones destaca sobre las demás por el uso insólito que Jesús realiza del verbo cỉní (ser). Así, en numerosos lugares del Evangelio

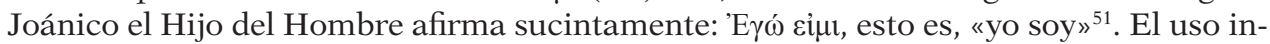
transitivo del verbo eỉuí recuerda enormemente a la respuesta que YHWH diera a Moisés cuando éste le preguntó por su nombre: "Yo soy el que soy»" La expresión castellana, mediada por la traducción latina (Ego sum qui sum) y en lógica continuidad con la tradición metafísica griega ${ }^{53}$ nos devuelve una interpretación esencialista en la que el ser de Dios se destaca sobre cualquier otra forma de ser en tanto que ens realissimum. Sin embargo, la exégesis puramente hebrea ha alumbrado distintas connotaciones que no podemos desatender. Así, resulta ya clásica la interpretación de F. Rosenzweig y M. Buber quienes traducen: Ich werde dasein, als der ich dasein werde ${ }^{54}$ que podríamos forzadamente traducir al castellano como «yo seré ahí-presente como aquel que estará [ahí presente]». Del mismo modo, Chouraqui ${ }^{55}$ traduce al francés je serais qui je serais («yo

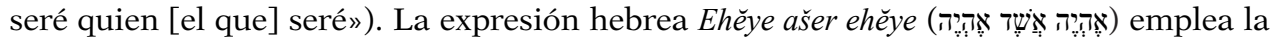
primera persona del imperfecto del verbo hawah, primitivo de hayah, que podría asimilarse a «devenir», «llegar a ser» (acaso en un sentido próximo al griego yívouaı referido en el Prólogo). En cualquier caso, la forma imperfecta denota que la acción no está terminada por lo que también existen traducciones en gerundio que interpretan el ser

andará en tinieblas, sino que tendrá la luz de la vida». Jn 8,18: «Yo soy el que doy testimonio de mí mismo, y el Padre que me envió da testimonio de mí».Jn 11, 25: «Le dijo Jesús: Yo soy la resurrección y la vida; el que cree en mí, aunque esté muerto, vivirá». Jn 15,1: "Yo soy la vid verdadera, y mi Padre es el labrador». Jn 15,5: «Yo soy la vid, vosotros los pámpanos; el que permanece en mí, y yo en él, éste lleva mucho fruto; porque separados de mí nada podéis hacer». Jn 15,1: «Yo soy la vid verdadera, y mi Padre es el labrador». Jn 15,5: «Yo soy la vid, vosotros los pámpanos; el que permanece en mí, y yo en él, éste lleva mucho fruto; porque separados de mí nada podéis hacer».

48 Jn 10,7: «Volvió, pues, Jesús a decirles: De cierto, de cierto os digo: Yo soy la puerta de las ovejas». Jn 10, 9: «Yo soy la puerta; el que por mí entrare, será salvo; y entrará, y saldrá, y hallará pastos».

49 Jn 10,11: "Yo soy el buen pastor; el buen pastor su vida da por las ovejas» y Jn 10,14: "Yo soy el buen pastor; y conozco mis ovejas, y las mías me conocen».

50 Jn 14, 6.

51 Jn 18,5: «Le respondieron: A Jesús Nazareno. Jesús les dijo: Yo soy. Y estaba también con ellos Judas, el que le entregaba». Jn 18,6: «Cuando les dijo: Yo soy, retrocedieron, y cayeron a tierra». Jn 18,8: «Respondió Jesús: Os he dicho que yo soy; pues si me buscáis a mí, dejad ir a éstos»; 8,24: "porque si no creéis que yo soy, en vuestros pecados moriréis». Jn 8,28: «Les dijo, pues, Jesús: Cuando hayáis levantado al Hijo del Hombre, entonces conoceréis que yo soy, y que nada hago por mí mismo, sino que según me enseñó el Padre, así hablo». Jn 9,9: «Unos decían: Él es; y otros: A él se parece. El decía: Yo soy.» Jn 6,20: «Mas él les dijo: Yo soy; no temáis».

52 Ex 3, 14.

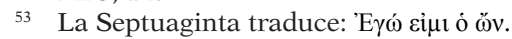

54 Así en su traducción de la Biblia. En Yo y tú M. Buber traduce Ich bin da als der ich da bin (yo soy ahí como el que ahí es). A su vez, Lutero, en su traducción de la Biblia atendió a la complejidad del texto hebreo para expresar ya en tiempo futuro: Ich werde sein der ich sein werde.

55 Paris: Éditions Desclée de Brouwer, 2010. 
de YHWH como un «ir siendo», por lo que la expresión podría también traducirse como "yo voy siendo el que voy siendo" ${ }^{56}$.

Si, como señalara Adolf Schlatter ${ }^{57}$, la expresión del Evangelista hubiera de interpretarse como la de un escritor bilingüe, podríamos enfrentarnos al Cuarto Evangelio como un texto que fue redactado en griego pero concebido en hebreo (y no así, como defendiera Burney, en arameo). Recogiendo el sentido que alumbra este paralelismo entre el 'E $\gamma \omega \dot{~ \varepsilon i ̉ \mu t ~ y ~ e l ~ N o m b r e ~(H a S h e m) ~ d e ~ Y H W H, ~ l a s ~ p a l a b r a s ~ d e l ~ P r o ́ l o g o ~ c o b r a n ~ u n ~}$ nuevo sentido al precisarse que, en efecto, el lógos era «en principio» para después llegar

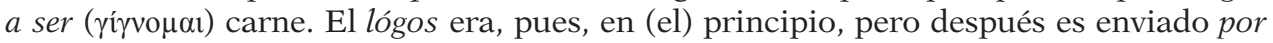

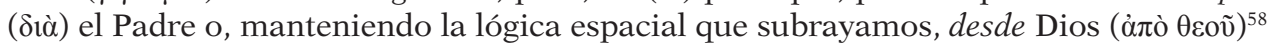
La marcada preocupación hebrea por el Nombre de Dios (quien es conocido, precisamente, por ser HaShem, esto es, El Nombre por excelencia) inaugura una concepción que no parece desvinculada de la noción de la Palabra (Dabar) y así tampoco, del lógos del Cuarto Evangelio. En el caso de Juan la importancia de la palabra e, incluso, de las palabras ( $\tau \grave{\alpha} \dot{\rho} \eta \dot{\mu} \alpha \tau \alpha$ ), se hace evidente habida cuenta que la Salvación depende exclusivamente de la creencia en dicha Palabra. Así, el propio Evangelio recoge al final que su redacción responde a un único propósito: a que a través de la Escritura creamos que Jesús es el Mesías, el Hijo de Dios, y para que creyendo tengáis (tengamos) vida en su

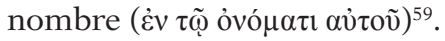

El vínculo entre la creencia y la palabra resulta evidente por cuanto la Verdad no sólo acontece sino que es expresada en la Palabra y a través de la Palabra. La Verdad en

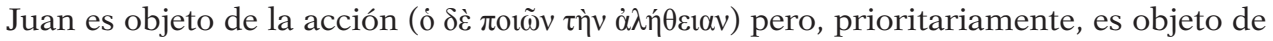
conocimiento a través de su expresión en la Palabra. Por ello, recoge el Cuarto Evangelio, la transición salvífica acontece en el conocimiento de la verdad como condición de apertura y salida de este mundo. Así, el Nazareno invoca en tiempo futuro: conoceréis

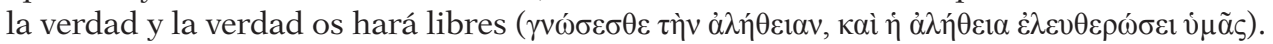
Ningún pasaje del Cuarto Evangelio condensa con tanta precisión y contundencia el íntimo vínculo entre la Verdad y la Palabra como aquel versículo en el que Jesús advierte:

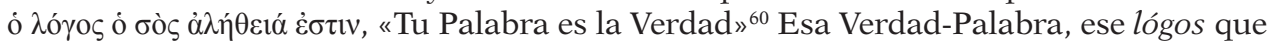
no es sólo verdadero sino que es fundamentación y constitución de la Verdad parece más griego que hebreo por cuanto Palabra, en este contexto, no parece hacer referencia a una forma imperativa como la Torá, una palabra que se hace verdad al convertirse en Ley. La Palabra que funda verdad en el Evangelio de Juan es precisamente lógos. Aquella lógica de la permanencia y la retención que antes mencionamos descubre que el decir de Jesús no era simplemente verdadero sino que se distingue como una verdad fundacional, como aquella verdad que resulta prioritaria por ser, precisamente, in principio. Así, cabría interpretar, la palabra de Jesús no es simplemente palabra verdadera sino que es aquello que, verdaderamente es palabra. La diferencia entre el «decir verdadero» —esto es, «decir verdad»— y el «verdadero decir» — decir verdaderamente— abre nuevas posibilidades de comprensión para ese binomio que identificaba el lógos con

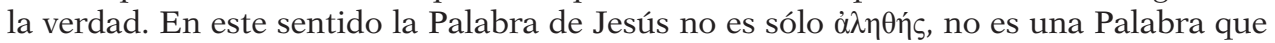
en su relación con el mundo se demuestre ni eventual ni necesariamente verdadera

56 SPItzer, L. «Soy quien soy», en Nueva Revista de filología hispánica, Año I, Número II, pp. 113-127.

57 Die Sprache und Heimat des vierten Evangelisten (1902) y Der Evangelist Johannes (1930).

58 Jn 3,4 .

59 Jn $20,31$.

60 Esta expresión es habitual en los cuatro Evangelios aunque su uso destaca en Mateo (quien la emplea veinticuatro veces) y en Juan (veinte veces). Marcos sólo la empleará once veces por las escasas cinco de Lucas. 
sino que es un lógos $\dot{\alpha} \lambda \eta \theta$ vós, un lógos fundador de verdad, una palabra —acaso la única- que pueda significarse no simplemente por su decir verdadero sino por ser lógos en un sentido genuino.

A partir de estos presupuestos resulta evidente que gran parte de la tradición exegética haya tratado de desentrañar los ipsissima verba del Rabino Nazareno sirviendo el decir de Cristo como canon fundacional de la Verdad, una Verdad que aunque se expresa en griego en el Cuarto Evangelio hereda incuestionablemente su matiz judío. El Evangelista se expresa en términos ambiguos al emplear en numerosas ocasiones el término $\alpha \hat{\jmath} \eta \dot{\theta} \varepsilon \alpha$ y al suscribir un uso del término perfectamente asimilable al de la tradición griega. Sin embargo, la Verdad del Hijo, en relación a su propio decir, se expresa

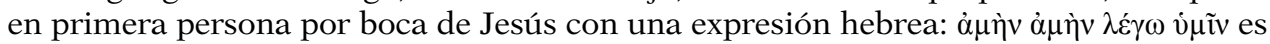
la fórumula empleada por Juan ${ }^{61}$ para enmarcar la enseñanza oral de Rabino de Nazaret que en castellano traducimos imperfectamente por «en verdad, en verdad os digo...».

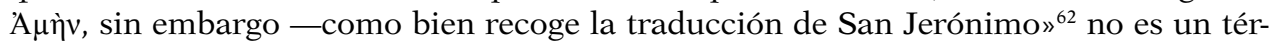
mino asimilable al término latino veritas por lo que adquiere perfecto sentido el hecho de que el Evangelista alterne la expresión griega y la expresión hebrea. La verdad del decir de Cristo se significa por el término "amén», una expresión hebrea (אֵָׁ) derivada del verbo amán (sustentar, sostener, reforzar...) del cual derivarán también los términos de emet (verdad, seguridad...) y emunah (fe, fidelidad...). La verdad de las palabras de Jesús se emparenta así con aquella otra verdad hebrea fundada sobre una Alianza como se subraya en distintos pasajes del Cuarto Evangelio ${ }^{63}$.

Con respecto al lógos, como hemos destacado, el Cuarto Evangelio insiste en un tiempo y en una tópica de la retención que marcará la transición salvífica del creyente. Jesús advierte que antes de su venida la palabra no residía en aquellos que posteriormente vieron y oyeron para, poco después, invitar a sus discípulos a permanecer en lógos. Así su exhortación es perfectamente clara trazando una identidad entre el amor, el lógos y su propia persona: "permaneced en mí», "permaneced en mi lógos», "permeneced en mi amor ${ }^{64}$. El Evangelio de Juan subraya la dimensión puramente lingüística del decir de Jesús, un decir que se expresa en el habla pero que, sin embargo, no agota otras implicaciones del lógos. El Hijo del Hombre se pregunta por qué no pueden reconocer su lenguaje y concluye que esta incapacidad para percibir o comprender ( $\gamma 1 \gamma v \omega ́ \sigma \kappa \omega)$ su habla

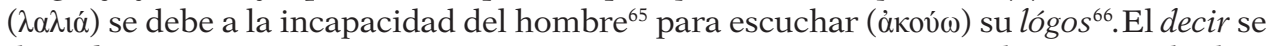

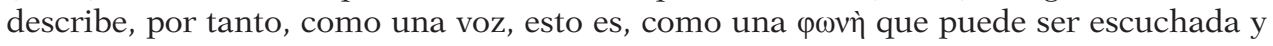
que, además, quedaba identificada con la verdad. De la mano de Aristóteles podríamos

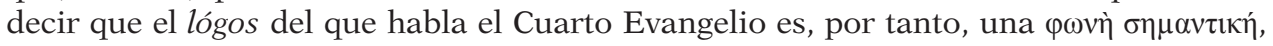
un decir cargado de significación verdadera. En tal caso, el hito que pauta la transición de éste al otro mundo viene demarcado por la escucha y la posterior creencia (o en línea con la tradición hebrea, diríamos, confianza) en la Palabra Verdadera. El que escribe

61 Y así también los otros evangelistas. Destaca el uso de Mateo quien emplea la expresión veinticuatro veces por once de Marcos y once de Lucas.

62 La Vulgata mantiene el término hebreo por lo que traduce la expresión como amen dico vobis, esto es, «amén os digo»...

63 Jn 12,$38 ; 15,25 ; 18: 32$.

64 En mí, Jn 15,4-7. En mi amor, Jn 15, 9. En mi lógos, 81.

65 Vid. de nuevo Fr. 1 Heráclito.

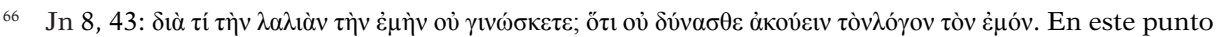
nos parece más certera la traducción de Reina Varela («¿Por qué no entendéis mi lenguaje? Porque no podéis escuchar mi palabra») que la de Cantera Burgos ("¿Por qué no reconocéis mi lenguaje? Porque no podéis aceptar mi doctrina). En Vulg.: quare loquellam meam non cognoscitis quia non potestis audire sermonem meum. 
subraya a lo largo de todo el Evangelio la importancia de la creencia como único requisito para gozar de la vida eterna lo que, según la tradición, demostraría la inspiración gnóstica del Cuarto Evangelio. No son las obras o las acciones sino la estricta creencia la que determinará la salvación del creyente: «el que cree en el hijo tendrá vida eterna» ${ }^{67}$ y la vida eterna no es otra cosa que conocer al Padre ${ }^{68}$. ¿Cómo interpretar, entonces, no sólo el significado del término lógos sino aquella significación del lógos mismo que lo

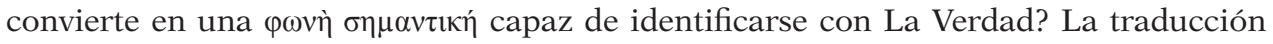
latina distinguió varios usos del término lógos y en su dimensión significativa lo identificó como sermo, esto es, como doctrina. Sin embargo, existe una alternativa posible y fecunda para caracterizar al lógos del Prólogo (aquel que era en Principio y devino carne) como un elemento intrínsicamente significante. A este respecto es esencial que la verdad se identifique no ya con las palabras ( $\dot{\varphi} \eta \mu \alpha \tau \alpha)$ enunciadas por Jesús sino con el lógos, un lógos que, dijimos, no se caracteriza meramente por su «decir verdadero» sino por distinguirse como el verdadero (y prioritario) decir.

Constatamos, por tanto, que el sentido o la función lógos es, propiamente, significar, esto es, manifestar o generar una señal que sirva como verdad habilitante y constitutiva de la creencia salvadora. Al hablar del lógos como verdad y al exigir, con Aristóteles, que

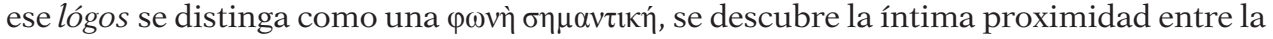
Encarnación del lógos y su significatividad para los hombres. Recordemos que $\sigma \tilde{\eta} \mu \alpha$, raíz

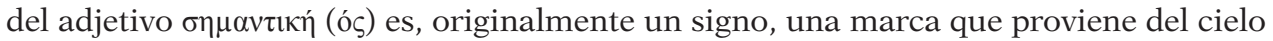
al modo en que Zeus dio a los troyanos la señal- $\sigma \tilde{\eta} \mu \alpha$ de la revancha ${ }^{69}$. No parece casual, por tanto, que el objeto de la creencia (o al menos, el medio a través del cual acontece la creencia) en el Cuarto Evangelio sea, precisamente, las «señales de Jesús». Algunas

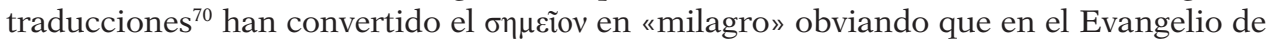
Juan no aparece ninguna vez el término habitual para designar los milagros y prodigios de Jesús $(\delta v v \alpha ́ \mu \varepsilon ı)^{71}$. Como señala Erdozáin ${ }^{72}$ de las dieciocho veces que el Evangelista

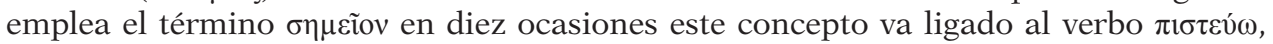
«creer, confiar...», por lo que la salvación que anuncia el Cristo del Cuarto Evangelio depende íntimamente de la actitud que se adopte frente a las señalas realizadas por el Hijo del Hombre sean bien interpretadas ${ }^{73}$. Esta posibilidad subrayada por Bultmann (a saber, que las señales sean bien interpretadas o mal interpretadas) determina el hecho de que la Salvación sea, ante todo, una cuestión hermenéutica. El acceso al otro mundo y la transición hacia la vida eterna quedan determinados por la actitud que se adopte con respecto a los signos que obró Jesús, signos de los cuales sólo somos testigos mediados a través de la Escritura.

67 3, 36. Cfr. Jn 3,18: «El que cree en él no será condenado». Jn 6,40: «El que cree en el hijo tendrá vida eterna». Jn 11, 25: "Yo soy la resurrección y la vida; el que cree en mí, aunque muera, vivirá; y todo el que vive y cree en mí no morirá jamás».

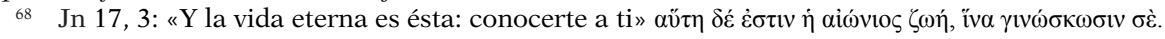

69 Il. VIII, 171.

70 E.g. Reina Varela (2010) o Nueva Biblia de los Hispanos (2005) Jn, 6,2.

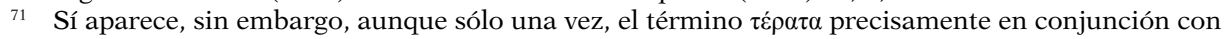

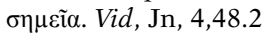

${ }^{72}$ «La función del signo en la fe según el Cuarto Evangelio». Analecta Biblica, 33, p. 2. Roma: Pontificio Instituto Bíblico, 1968.

${ }_{73}$ En un texto ya clásico, Chalier advierte: «est un geste posé par le Christ et dont la vue memme doit conduire à la foi» // "el semeion es el gesto obrado por Cristo cuya vista (orao) conduce a la creencia». "La notion de signe (semeion) dans le IV Évangile» en Revue des Sciences Philosophiques et Theologiques, 43 (1959), p. 436. 
Nuevamente de la mano de Bultmann cabe destacar el modo en que el Cuarto Evangelio equipara la obra de Jesús con su función sígnica. El Jesús del Evangelio de Juan no se destaca por su dimensión «factativa» sino por una labor sígnica, simbólica ${ }^{74} \mathrm{O}$, incluso valdría decir, lingüística. El mensaje salvífico de Jesús no se caracteriza ni por el anuncio ni por la prescripción de un complejo cuerpo doctrinal por lo que cuando sus interlocutores le preguntaron "¿qué tenemos que hacer para realizar las obras de Dios

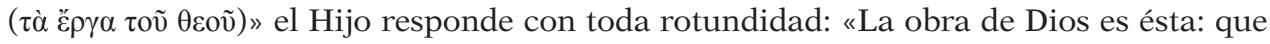
creáis en el que me envió». Ya apuntamos que la creencia toma por objeto precisamente las señales, una manifestación inmanente que en su función significativa rebasa su puro acontecer material (aquí y ahora) para signar aquella otra verdad trascendente que permite identificar el lógos con la verdad. No en vano, la traducción latina de las señales ( $\tau \alpha \grave{~} \sigma \eta \mu \varepsilon i \alpha)$ es signa, el mismo término empleado por San Agustín en aquella dupla que

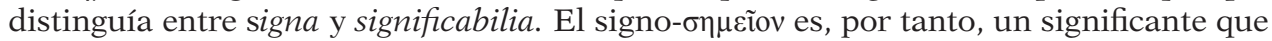
remite necesariamente hacia un significado. La función del Enviado se destaca, por tanto, por su labor significativa, por ejercer — como destaca insistentemente el Evangeliode puerta, de camino o de mediación. Así Jesús alcanza a decir «aunque no me creáis en mí, creed a las obras mismas ${ }^{75}$ pero ese «creer a las obras» se determina causalmente a

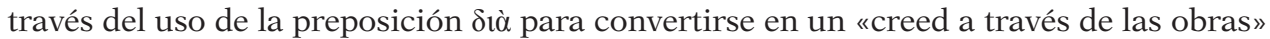
unas obras que, según vimos, quedan identificadas con las señales o los signos de Cristo.

Vemos, por tanto, cómo el lógos encarnado retiene una función significante que no descansa - o no, al menos, exclusivamente- en la significatividad de las palabras $\dot{\rho} \eta \dot{\mu} \alpha \tau \alpha$ de la enseñanza oral de Cristo. La obra en vida del lógos encarnado se caracteriza

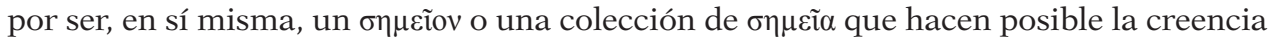
salvífica en aquella otra realidad signada que trasciende el puro acontecimiento material, puntual y concreto de la vida del Hijo. Este giro habría de reorientar la atención del intérprete no ya hacia la Escritura sino hacia el objeto de la escritura misma. La narración evangélica no sería, así, el interpretandum original sobre el que centrar los esfuerzos hermenéuticos al ser ya una suerte de interpretans. Cierto es que, en tanto que testigos mediados, sólo podemos acceder al objeto de la interpretación a través de una narración imperfecta que de un modo confeso advierte que sólo retiene una parte de las señales obradas por Cristo. Sin embargo, esta precaución valdría para reasignar un valor y una función específica a la escritura en la tradición cristiana ${ }^{76}$ y para interpretar, una vez más, el oscuro sentido del decir joánico.

\section{CONCLUSIÓN}

Resolviendo la hipótesis inicial con la que se abrió el presente trabajo parece, si no razonable, sí al menos posible reconstruir el sentido del lógos en el Evangelio de Juan a partir de su caracterización sígnico-lingüística. Así, el lógos ubicado originalmente in principio demuestra su función significativa y vehicular al situarse no ya con ( $\mu \varepsilon \tau \alpha$ ) Dios sino hacia ( $\left.\pi \rho \varsigma_{\varsigma}\right)$ Dios. Aquella palabra es el acontecimiento original con respecto al cual

74 Garía Moreno señala que «la noción de signo y la noción de símbolo pueden hacerse equivalentes en el evangelio de Juan (todo símbolo es un signo aunque no todos los signos son un símbolo)», Temas teológicos en el evangelio de Juan, Op. cit. p. 28.

75 Jn 10, 37. Cfr. Jn 14, 11.

${ }_{76}$ No en balde, J. Ratzinger en la exhortación apostólica Verbum Domini, VII, señaló que, propiamente, el Cristianismo no es una religión del Libro. 
debe situarse el creyente y del que cabe realizar una interpretación correcta asumiendo, en toda su extensión, la significatividad de una vida que se hace precisamente humana a través de la Encarnación. Este lógos no sería equiparable a aquella Palabra de Dios del Génesis que antecede a la Creación y que adelanta, en su propia formulación, la prioridad de la palabra sobre la cosa por cuanto fue antes el imperativo divino expresado en palabras que la Creación misma. El lógos de Juan se hace carne para convertir su obra

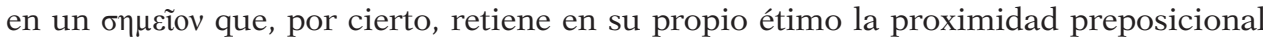
que mantenía la traducción latina del $\pi \rho o ́ \varsigma$ por apud. La raíz indoeuropea *sem significa, justamente, «unidad», una unidad que posteriormente mantuvo en griego ( $\sigma \nu \mu)$ ese matiz de continuidad o yuxtaposición íntima que impondría unidad entre los dos elemen-

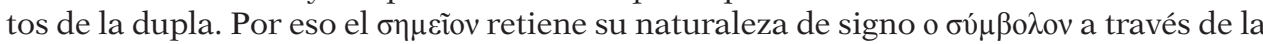
íntima unión entre el signo y su significado. Así ocurre entre el Padre y el Hijo, reunidos

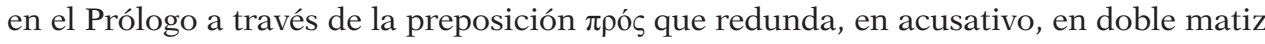
de direccionalidad y proximidad.

Con todo, leyendo las últimas palabras del Cuarto Evangelio, parece que la narración joánica es ya un texto vicario, interpretans de un interpretandum primario como fue aquella vida del Hijo que, como todo Lógos, se distingue por reunir una colección de señales que, en su unidad, inauguran un sentido. Tal es el sentido que se dirige hacia Dios y que distingue la identidad del Hijo como un "camino", como un ódò de la kénosis se presenta a sí mismo haciendo uso del verbo sỉ en forma intransitiva. La Vida del Hijo se resuelve así como un texto o, si se prefiere evitar la anacronía en la metáfora, como un acontecimiento vital digno de ser creído, comprendido e interpretado. Esto es: seguido. El Evangelista, adelantándose a su tiempo prefigura así, tantos siglos antes, una hermenéutica de la existencia cuyo último sentido será «conocer al Padre». El Lógos se resume así en su pura direccionalidad hacia, en el vaciamiento de toda determinación sustantiva o doctrinal para agotarse en su forma (su función, su obra) vehicular y significativa por cuanto el signo parece aquí enteramente deudor de lo signado. A partir de esta interpretación podrá cobrar también un nuevo sentido la que acaso sea la metáfora más perfecta de ese conocimiento mediado y de la que hoy sabemos por voz de Pablo de Tarso: «ahora vemos mediante un espejo, oscuramente, pero entonces veremos cara a cara» ${ }^{77}$.

Universidad Autónoma de Madrid

Diego S. Garrocho Salcedo

diego.garrocho@uam.es

[Artículo aprobado para publicación en noviembre de 2013]

77 Jn 17,3. 87 Cfr. I Cor 13, 12. y 2 Cor 3:18. 